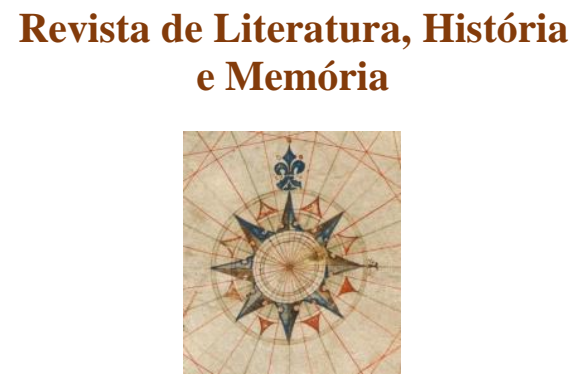

Seção: Pesquisa em Letras no contexto Latino-americano e Literatura, Ensino e Cultura

ISSN 1983-1498

VOL. 16 - No 27 - 2020

U N I O E S T E / CA S C A V E L - p. 278-294

\section{A BUSCA DE 'BRASILIDADE' INACABADA EM DONA FLOR E SEUS DOIS MARIDOS POR JORGE AMADO: PARA ALÉM DE MESTIÇAGEM E DUALISMO}

\author{
La búsqueda de 'brasilidad' inacabada \\ en Doña flor y sus dos maridos por Jorge Amado: \\ más allá de mestizaje y dualismo
}

RESUMO: O presente trabalho tem por objetivo analisar Dona Flor e seus Dois Maridos (1966) com especial enfoque em relação à mestiçagem. Na obra de Jorge Amado, o povo baiano aparece sob a visão utópica da cidade como um microcosmo do país. A ideia da brasilidade do autor baseia-se sobretudo na mestiçagem tanto racial quanto cultural. A ideia do autor que vê a brasilidade como um produto da mestiçagem, contudo, revela um dilema, por exemplo, na idealização da beleza da "mulata" e da cultura brasileira, música alegre. Entanto, a cidade bahiana na obra é entendida como uma expressão da brasilidade, um dualismo de valores distintos incluso contraditórios, às vezes, de acordo com os ensaios de Roberto DaMatta que aponta a dona Flor como um ser intermediador desse dualismo. A interpretação da personagem amadiana como uma forma de brasilidade continua. $\mathrm{O}$ filme de Bruno Barreto produzido em 1976, como um intertexto do romance, mostra que existe uma janela como um terceiro elemento simbolizado que alivia a tensão entre os dois valores antagônicos da cultura da cidade e do país.

PALAVRAS-CHAVE: Dona Flor; Mestiçagem; Dualismo; Brasilidade.

RESUMEN: El presente artículo analiza Doña Flor y sus dos maridos (1966) desde el enfoque del mestizaje, como uno de los caracteres brasileños denominado 'brasilidad'. En la obra de Jorge Amado, el pueblo de Bahía aparece como un microcosmos del país bajo la visión utópica de la ciudad. La idea del autor que ve la 'brasilidad' como un producto del mestizaje tanto racial como cultural, revela un dilema que se puede apreciar, por ejemplo, en la idealización de la belleza de la mulata por el narrador y la música alegre. Por otra parte, la ciudad bahiana se entiende como una expresión del caracter brasileño, un dualismo de valores distintos incluso a veces contradictorios, según Roberto DaMatta quien señala a doña Flor como un intermediario del dualismo. La interpretación de doña Flor como una forma de brasilidad continúa en forma diferente. En la película "Doña Flor y sus dos maridos" (1976) de Bruno Barreto como un intertexto de la obra amadiana, la presencia de la ventana se simboliza como un tercer elemento que alivia la tensión causada por el dualismo de la cultura de ciudad-país.

PALABRAS-CLAVE: Dona Flor; Mestizaje; Dualismo; Brasilidad.

\title{
INTRODUÇÃO
}

Jorge Amado (1912-2001) é considerado um escritor do povo do Brasil, sobretudo, pelo povo de Bahia, onde o autor nasceu, cresceu e passou a sua vida. Amado é um dos

\footnotetext{
${ }^{1}$ Doutoranda em Literatura Hispano-americana da Seoul National University (SNU). Bolsista de Futuros investigadores pela SNU e BK21. Professora visitante pela Korea Foundation no Curso de Coreano na Faculdade de Filosofia, Letras e Ciências Humanas na Universidade de São Paulo (USP). (2014-2018).
} 
escritores brasileiros mais lidos no mundo - suas obras foram traduzidas para vários idiomas inclusive para a língua coreana. As três obras da segunda fase do autor, Teresa Batista Cansada de Guerra (1972), Gabriela, Cravo e Canela (1958) e também Dona Flor e seus Dois Maridos (1966), em ordem cronológica de publicação na Coreia, foram apresentadas aos leitores coreanos. Chamado como "embaixador simbólico do Brasil" (SCHWARCZ, 2009, p. 37), Amado foi apresentado na Coreia como um dos representantes da literatura brasileira e passou a formar uma parte do imaginário sobre o Brasil.

Dona Flor e seus Dois Maridos, (doravante referida como Dona Flor) conta-nos a história de uma mulher baiana, ao longo das décadas de 1930 e 1940, dividida entre dois amores, cada um representando um valor distinto da cultura em Salvador. A narração não enfoca apenas os acontecimentos em torno de Flor, mas também forma um conjunto de histórias mais complexas que nos revela a cidade baiana, seu povo, costumes, mentalidade e rotinas.

Apesar de, a partir da figura de dona Flor, junto com a excentricidade da personagem feminina e o elemento fantástico no ambiente carnavalesco da cidade, a obra discutir temas como posição social de mulher, liberdade cultural e sensualidade, este trabalho se aterá à releitura da obra amadiana do ponto da vista da "brasilidade" como uma imagem nacional, através da representação da sociedade de Salvador. Podemos observar que a ideia de identidade brasileira do autor é baseada na mestiçagem, e também no dualismo da sociedade diante dos valores distintos formados pelas experiências históricas e culturais dessa cidadepaís. Tentaremos analisar o mestiço como um produto de sincretismo racial e cultural, representado na obra através da visão utópica da sociedade brasileira. Para esse fim, abordamos as considerações de Roberto DaMatta, especialmente sua análise sobre a figura de dona Flor, como um ser intermediário mulato, e o dualismo da casa e da rua na sociedade brasileira, discutidos no livro O Que Faz o brasil, Brasil? (1986). Note-se que nos últimos anos, uma coleção de livros que se tratam considerações sobre a identidade cultural e social do país está sendo apresentada aos leitores coreanos. Sendo a primeira A história concisa do Brasil (1999) de Boris Fausto, foram publicadas Métaphysique scannibales (2009) de Eduardo Viveiros de Castro e Raízes do Brasil (1936) de Sergio Buarque de Holanda, além da obra de Roberto DaMatta.

Com o propósito de oferecer um trabalho de maior consistência, incluímos também a versão cinematográfica do romance. Analisamos a interpretação da obra pelo diretor brasileiro Bruno Barreto no filme Dona Flor e Seus Dois Maridos (1976), tomando-o como um intertexto da obra amadiana. As cenas de nosso interesse são da construção visual de espaços: 
a casa, a rua e a janela como elementos que simbolizam o dualismo da cultura brasileira.

\section{UMA TENSÃO ATRÁS DA VISÃO UTÓPICA DA CIDADE/PAÍS}

Flor é diretora de escola culinária, "A escola de Sabor e Arte”, uma mulher cuja paixão (tanto sexual quanto vital) logo vai ser apreciada por seu primeiro amor, Vadinho. O marido possui charme sedutor, sendo um sujeito portador de todos os tipos de malandragens: viciado em jogos, mulherengo, preguiçoso etc. Após sete anos de casamento, Vadinho morre em um ataque cardíaco quando divertia-se no carnaval da praça Dois de Julho. Após um ano de luto pelo finado marido, ela encontra seu novo amor, o farmacêutico doutor Teodoro. Este segundo marido é sistemático, e dona Flor descobre uma forma de vida diferente e passa a ter uma vida mais estável e ordenada, sendo também introduzida na vida social burguesa. Nesse segundo casamento, tudo contrasta com a vida em comum com o primeiro marido. Em questão de paixão sensual, porém, Flor sente falta do primeiro. É assim que Vadinho volta à casa em forma de um espírito que apenas a mulher consegue enxergar. A presença de Vadinho faz a mulher sofrer: ele não para de seduzi-la sexualmente insistindo "prioridade" por ser o primeiro marido. Isso põe dona Flor em confusão entre a fidelidade ao seu legítimo marido vivo e a saudade pela sensualidade do primeiro amor. Sendo uma mulher mais independente, tanto como indivíduo como na sociedade, ao final, Flor assume sua vontade de ficar com os dois amores, duas formas de vida distintas em todas as maneiras.

A história de dona Flor não pode ser lida simplesmente de um amor (fantástico), em relação triangular, pois envolve também as histórias de suas famílias, de vizinhos, de todas as pessoas da cidade como um espaço reduzido do Brasil. Assim, aparecem diversos personagens de origens diferentes que nos revelam a diversidade de cidadãos de Salvador daquela época. O que se destaca na narrativa acerca dos personagens-cidadãos é o fato de que a maioria deles não oculta a sua identidade racial que é descrita por meio de suas características físicas. Eles aparecem como negros, brancos ou mulatos: "a negra Juventina", “o negro Arigof”, "as mulatinhas Catundas”. Já os cidadãos imigrantes são marcados por sua nacionalidade: argentinos (Dona Nancy), espanhóis (Mendez e Ramiro), portugueses (Celestino), estadunidense (Dona Gisa, "a gringa"), entre outros. Essas descrições raciais e nacionais são repetidas em todas as ocasiões em que aparecerem os personagens. $\mathrm{Na}$ vizinhança do casal Flor e Vadinho, também há diversidade de profissões: desde o dono de loja de sapatos, empregados de cassino, prostitutas, funcionários públicos, banqueiros, donas de casa, empregadas domésticas, poetas inclusive professores universitários. 
Vadinho, "bastardo de uma família importante, os Guimarães" (AMADO, 2008, p. 30, cito esta edição), é branco de cabelo loiro. É funcionário público, mas passa mais tempo na rua e no cassino do que na repartição. Após sua morte repentina, segue o velório que se torna uma ocasião na qual quase a metade da cidade se reúne. $\mathrm{O}$ defunto é comemorado por todos os tipos de amigos e vizinhos da cidade. Tanto entre os moradores da rua do casal quanto entre os amigos e conhecidos pela relação social, há variedade de classes: "os vizinhos, os ricos e os pobres, os remediados também", "familiares dos grandes e dos pequenos, dos respeitáveis e dos irresponsáveis" (p. 32-33).

A cidade baiana, dessa maneira, aparece como um espaço onde há a coexistência de todos os tipos humanos; a convivência cotidiana entre eles não é prejudicada por uma suposta hierarquia de profissão ou pela cor da pele, tampouco pela nacionalidade. O fato interessante é que, na verdade, Vadinho não é uma pessoa importante que mereça tanta visibilidade social. Não podemos negar que ele possui mais vícios e defeitos do que virtudes. Contudo, apesar da separação das pessoas em suas classes sociais, nacionalidades ou origem racial, para o protagonista é possível construir uma relação de "amizade" próxima e transitar livremente entre todos. No centro desse pequeno mundo, a figura de Vadinho serve como um mediador do povo (mesmo no seu próprio velório), um conetor da cidade, o típico "malandro" que “despertara para sempre do Carnaval da Bahia" (p. 22). Agora assim como no carnaval, o velório de Vadinho torna-se um espaço simbólico da cidade onde é possível a coexistência dos cidadãos, sem nenhum tipo de discriminação-

Segundo De Oliveira (2013, p. 210-222), que prestou atenção ao simbolismo da cidade de Salvador como uma cidade ideal e sua importância na criação literária de Amado, a questão racial em Dona Flor está implícita. Ao ser comparada com outras obras do autor, principalmente, a Tenda dos Milagres (1969), em Dona Flor, o romancista nunca toma uma posição clara nos conflitos raciais. É interessante sua análise da praça Dois de Julho, que aparece como um espaço-símbolo, onde não há nenhum tipo de conflito entre as diversas raças, tornando-a um paraíso perdido. A cidade vira um espaço pós-raça, um modelo de Salvador ideal, onde a miscigenação ocorre em um sentido maior do que a mistura social, racial e econômica (DE OLIVEIRA, 2013, p. 222). A praça é onde acontece o carnaval, uma das produções mais fortes de mistura de várias culturas no país e também um meio de pessoas das mais diferentes origens se expressarem livremente, apagando assim tensões tanto sociais quanto individuais. Esse espaço, de uma maneira irônica, transforma-se no lugar de falecimento (física, não espiritual) de Vadinho durante a festa em que se comemora a vida.

No entanto, por trás dessa visão utópica da cidade, encontramos a existência de certa 
hierarquia social que divide a cidade. Dona Rozilda, a mãe da Flor, possui um desejo forte de permanecer na classe média ou até mesmo de elevar a sua posição social. O desejo material da mãe autoritária serve como o parâmetro de sua decisão ao permitir casamento de Rosália, sua filha mais velha:

[...]os arrotos de burguesia de dona Rozilda com seus caprichos de grandeza, a ambição de conviver com famílias importantes, de penetrar nos círculos de gente apatacada. Embirrava dona Rozilda com a maioria dos vizinhos, desprotegidos da sorte — balconistas de lojas e armazéns, empregados de escritório, caixeiros e costureiras. Desprezava essa gentalha incapaz de esconder sua pobreza (AMADO, 2008, p. 58).

Dona Rozilda não recusa o casamento da filha porque o genro, Antônio Morais, apesar de não ter "sangue nobre", deu-lhe a impressão de estar seguro financeiramente, por ser um bom mecânico. O desejo capitalista da mãe faz-nos perceber a existência de hierarquia social de maneira implícita, apesar da harmônica visão de diversidade racial e cultural na cidade.

Além disso, encontramos um certo ambiente de segregação por classe social refletido na divisão entre "cidade baixa" e "cidade alta". Dona Rozilda insiste em permanecer na Lareira do Alvo, apesar de não ter condição de manter a vida de classe média após a morte do seu marido. Em uma cena em que dona Flor visita "cidade baixa", à procura de dona Dionísia para descobrir a verdade sobre relação ilegítima entre ela e Vadinho, no caminho até a casa da dona Dionísia, mulher de classe baixa com características afrodescendentes, destaca-se a descrição das ruas, das crianças na rua e das prostitutas, descuidadas. Nessa forma de residência do bairro, entrevemos a outra face da cidade baiana.

O encontro das duas mulheres de classes distintas dá-se pacificamente, já que tinha havido apenas uma simples confusão por seus maridos terem o mesmo nome. Mesmo o desfecho sendo pacífico, é difícil ignorar a outra "cara" da cidade onde os cidadãos mais pobres e de pele mais escura estão mais concentrados. Assim o contraste entre o mundo de dona Flor e seus amigos e outro lado da cidade passa a ser bastante forte. Esse episódio serve como uma mostra da existência de divisão de espaços pela diferença de classe social e econômica.

\section{MESTIÇAGEM IDEALIZADA E MEMÓRIA COLETIVA}

Apesar de todas as formas de vida na cidade, encontramos no estilo de vida de dona 
Flor e seus maridos uma forma típica e idealizada de baianos: um ser "mulato", de categoria racial, e de classe média, em condição econômico-social. As protagonistas femininas dos romances de Amado foram discutidas em relação à imagem de mulata como raça, sua sensualidade e seu poder. Contudo, tem sido pouco discutida a representação amadiana de "mulata" em relação à imagem do país.

Em Dona Flor, a beleza da mulher é destacada nas descrições físicas como cor de pele escura, cabelo negro e a categoria racial "mestiça" ou "mulata". As descrições da aparência física das personagens femininas e elogios à sua beleza pelo narrador são encontradas com frequência. Vejamos o caso de dona Flor e sua irmã Rosália:

[...] pequena e rechonchuda, de uma gordura sem banhas, a cor bronzeada de cabo-verde, os lisos cabelos tão negros a ponto de parecerem azulados, olhos de requebro e os lábios grossos um tanto abertos sobre os dentes alvos. [...] Com sua tez mate de cabo-verde, suave e pálida, [Rosália] era a branca mais autêntica entre todas aquelas finíssimas brancas baianas apuradas em todos os tons do moreno; aqui entre nós, que ninguém nos ouça, mestiças da mais fina e bela mulataria! (AMADO, 2008, p. 65, grifo nosso).

A partir desse fragmento destacamos que os traços físicos são elementos importantes para apresentar um personagem. No caso da Rosália, sua beleza é destacada pela cor da pele de tom mais claro. O estereótipo de mulher baiana, descrita pela cor da pele, pelos cabelos, pelos lábios e pelos olhos, são frequentes nas obras amadianas: Tereza, em Tereza Batista Cansada da Guerra (1972); Lívia, em Mar Morto (1936); Otália, em Os Pastores da Noite (1964) (SCHWARCZ, 2009, p. 40). Em Dona Flor, a própria voz do narrador que sussurra nos ouvidos dos leitores: "ninguém nos ouça". Essa cena mostra, ironicamente, que ele mesmo afirma a falácia dessa afirmação sobre a descrição exagerada dos traços da mulher e, assim, da idealização da beleza feminina.

Em uma cena de festa, onde se realizam concertos, as cantoras norte-americanas, The Honolulu's Sisters, as irmãs Jô e Mô, apresentam-se junto com as cantoras brasileiras, Catundas. As cantoras de ambos os países são afrodescendentes, e suas músicas cantam memórias sobre o passado de escravidão.

Vieram depois The Honolulu's Sisters com um canto poderoso e triste, gemido de negros em correntes, reza de escravos, dor e revolta de homens humilhados. Até o sexo era triste, até os corpos tão belos, pensou dona Flor. As mulatinhas Catunda, desafinadas e modestas, pareciam um soar de guizos, um trinado de pássaro, um raio de sol, corpos de viço e saúde em comparação a Jô e Mô com 
seu lamento sem esperança. As Catundas dançavam em preceito aos orixás, aos alegres e íntimos deuses negros, vindos da África e na Bahía cada vez mais vivos. As negras americanas dirigiam sua súplica aos austeros e distantes deuses brancos dos senhores, impostos aos escravos no lanho das chibatas. Umas eram o riso solto, as outras o pranto desolado. [...] Queria ouvir o canto puro e doloroso, sem misturar à sua grandeza a tara das mulheres, sua doentia condição, sua sina. Música de sangue derramado, látego de fogo (AMADO, 2008, p. 189-190, grifo nosso).

Lembramos os fatos históricos de que o estado de Bahia foi o lugar onde floresceu a economia de produção de cana-de-açúcar e, por este motivo, chegaram ao estado mais escravos africanos do que a outros lugares do Brasil. O país foi um dos destinos mais comuns da diáspora africana e foi onde o sistema escravagista perdurou até a abolição tardia em 1888 (GATES, 2011, p. 18). Ao longo da história do estado, a cidade de Salvador virou o espaço mais forte da cultura africana. A música e a dança são as formas de expressão da sua identidade cultural, em que está mais bem conservada a memória do passado do povo.

Segundo Granados Sevilla (2016, p. 151-166), a sonoridade se destaca em marco social por seu relacionamento com o espaço e o tempo. Esse conceito está baseado na memória coletiva de Maurice Halbwachs: "cada memória individual é um ponto de vista sobre a memória coletiva, que este ponto de vista muda conforme o lugar que ali eu ocupo, e que este lugar mesmo muda segundo as relações que mantenho com outros meios" (HALBWACHS, 1990, p. 51). Portanto, Granados Sevilla adaptou a memória coletiva afirmando que é na música que estão reunidos os fragmentos do passado tanto de indivíduos quanto do coletivo:

El sonido es un producto de determinado tipo de relaciones sociales y económicas, se inscribe en una trama simbólica cada, supone determinado tipo de relaciones de dominación entre hombres y entre hombre y naturaleza. [...] El sonido, en su producción, interpretación y funciones que desempeña tiene un carácter social. [...] La música es, antes que nada, una práctica social, un hecho colectivo (SEVILLA, 2016, p. 159-161).

Neste sentido, podemos dizer que tanto nas músicas das Honolulu's Sisters quanto das irmãs Catundas estão refletidas as memórias do passado dos escravos de cada país. Lembramos que a cultura africana chegou por meio da força ao país. Embora os escravos tenham ficado sem voz por muito tempo na história, percebemos a sua memória baseada na própria experiência em forma de ritmos, sentimentos e notas na sua música e dança.

Granados Sevilla afirma que o ato de escutar a música inclui a relação entre os 
produtores, expoentes e público. Inclusive está, nesse ato, a relação de "la transmissión de mensajes" (SEVILLA, 2016, p. 160). Como ouvinte das canções (também assistente de danças), dona Flor tem o papel de relembrar e reconstruir o passado da memória coletiva pela qual ela recebe e interpreta a mensagem transmitida pela música. No entanto, através da voz de dona Flor, o narrador onisciente simplesmente deduz a imagem das canções como um contraste entre "sangue derramado", "correntes" (as norte-americanas) contra "raio de sol", "corpos de viço e saúde" (as brasileiras). O contraste de sonoridade está simplificado também, como "látego de fogo" e "gemidos de negros" das primeiras contra "soar guizos" e "trinado de pássaros" das segundas. Como a intérprete das mensagens das músicas, dona Flor analisa e avalia os passados: a memória coletiva "alegre" de escravizados brasileiros contra a memória coletiva "triste" dos norte-americanos.

As pesquisas históricas mostram certa diferença entre a experiência dos escravizados em ambos os países. Segundo Gates Jr., as políticas de segregação nos Estados Unidos foram, relativamente, mais cruéis do que as do Brasil. Por custo muito mais barato de importação da África, os escravizados no Brasil são tratados de jeito mais brutal enquanto os levados aos Estados Unidos foram tratados relativamente melhor (GATES, 2011, p. 18-19). Este fato histórico contrasta com a consciência histórica revelada na narração amadiana, já que nela parece a experiência brasileira menos cruel do que a norte-americana.

Apesar disso, sabemos que a experiência histórica não pode ser objeto de comparação. Essa questão leva-nos a pensar a ideia de identidade cultural brasileira do autor. Podemos encontrá-la nas palavras do autor; "Todo Brasil se resume en una palabra: mistura. Somos productos de la mistura; todo se mezcla en Brasil, las sangres, las razas, las costumbre, las religiones, los dioses" (MARRAS, 1992, p. 168). Assim, podemos dizer que a imagem da cultura brasileira construída na obra amadiana enfatiza o conceito de cultura de mestiçagem, do povo mestiço. É por essa razão que abundam os elogios da beleza da mulher mestiça, uma prova positiva de miscigenação racial. Os cantos e danças das irmãs Catundas de matiz africana são tratados como os produtos de mestiçagem cultural. Essa visão utópica de mestiçagem contrasta com a cultura negra norte-americana, na qual a memória de escravidão é mais bem conservada sem a "mistura" com outras memórias, segundo as palavras do narrador.

Nas palavras do romancista, encontramos o porquê de sua insistência na idealização de mestiçagem: 
[...] soy escritor en un país cuya cualidad característica es el mesticismo, la fusión de razas, la confluencia de distintas corrientes sanguíneas. Aquí se han mezclado todas las razas y de ahí ha surgido una cultura mestiza y una civilización mestiza [...]. No se puede dar entre nosotros una democracia, una democracia política si no crece y se basa en lo que llamo nuestra democracia racial (LORENZ, 1972, p. 405, grifo nosso).

Para Jorge Amado, a sociedade brasileira precisa ser "mestiça", e nesta sociedade deve ser realizada a "democracia racial", ideia que nasceu com Gilberto Freyre e logo foi utilizada para apoiar o projeto nacionalista nos anos 1930 durante o governo de Getúlio Vargas. Em busca da "brasilidade", a ideia de miscigenação descobriu o valor positivo nas heranças culturais de índios e escravos africanos. Como seu resultado, o "mestiço" foi considerado como representante racial da identidade nacional do povo brasileiro. Contudo, a ideia de democracia racial é criticada como um "mito": em sentido de nacionalismo, o "mulato" é uma identidade racial idealizada e integralizada que encobre as diferenças entre vários tipos de etnias e culturas. Enfim, a miscigenação resultou em "a more sophisticated version of whitening compatible" (DE CASTRO, 2002, p. 61). De acordo com Lilia Moritz Schwarcz, a ideia de democracia racial representada na obra amadiana é diferente da ideia de Freyre. $\mathrm{O}$ que Schwarz preferiria chamar "democracia racial à amadiana" é um mundo onde convivem harmonicamente todos os povos sem estar clara a hierarquia racial entre brancos, negros e indígenas (SCHWARCZ, 2009, p. 37-41). Apesar disso, a idealização de mestiçagem como a identidade brasileira tanto racial quanto cultural representada nessa obra amadiana causa, de uma maneira paradoxal, um dilema em relação ao passado histórico que forma base da cultura brasileira. Enfim, sabemos que não há memórias nem identidade mais "alegres" ou "tristes" que outras.

\section{DUALISMO OU CONFLITO ENTRE DOIS VALORES}

O socioantropólogo Roberto DaMatta reconheceu o simbolismo da figura de dona Flor em relação à sociedade brasileira e sua complexidade. Em seus ensaios "Dona Flor: a Relational Novel” (1982), “A Ilusão das Relações Raciais” em O Que Faz o brasil, Brasil? e no posfácio do romance (2008), dona Flor é apresentada como uma mediadora numa relação triangular. Segundo DaMatta, comparado a "dois”, "o três engendra um resto ou foco, inventa um outro elemento irredutível à dualidade que institui a gradação e, fazendo nascer o elo hierárquico, restabelece o todo" (DAMATTA, 2008, p. 466). No ensaio “A ilusão das relações 
raciais", esta relação triangular se aplica à questão de raça. Aqui DaMatta toma dona Flor como um mulato, um ser mediador entre as três raças do Brasil:

Se o mulato é um ser intermediário e ambíguo, uma espécie de Dona Flor das relações raciais brasileiras, categoria que existe de fato e de direito na ideologia social da sociedade e se legitima precisamente por instituir o intermediário e a síntese dos opostos como algo positivo (DAMATTA, 1986, p. 42).

Eis um ponto interessante sobre os livros de Roberto DaMatta. Existe uma nova edição do livro $O$ Que Faz o brasil, Brasil?, com um título diferente, porém com pouca alteração do conteúdo. A nova edição se intitula $O$ Que é o Brasil e foi publicada em 2004 pela mesma editora da primeira versão do livro. No capítulo desse livro novo, "Um racismo à brasileira", há partes excluídas da primeira versão. Em geral, na nova edição, destaca-se um tom mais acalmado à crítica de "mito de democracia social” e de racismo. Também nessa última versão, a menção de dona Flor como uma espécie mestiço mediador foi excluída.

A visão da sociedade brasileira com base no dualismo, o conflito entre dois é o que promove toda a história de amor de Flor, sua vida cotidiana e também todo no povo da cidade. Após um ano de luto pelo primeiro marido, dona Flor casa-se com o doutor Teodoro, o homem sistemático e organizado. Porém, a vida sexual organizada demais não satisfaz a mulher, o que provoca a volta de Vadinho à casa como fantasma. A partir da volta do primeiro amor, Flor entra em angustia diante do conflito entre o desejo sexual e a consciência moral. A personagem de Flor vira uma alegoria de "batalha do espírito com a matéria": "Não era mais uma pessoa só e igual, inteira e íntegra: estava dividida em duas, a honesta e a salafrária, seu reto espírito de um lado, do outro a matéria em ânsia. Um desacordo" (AMADO, 2008, p. 424). Dona Flor fica entre dois amores - entre a matéria, a vida estável e burguesa representada por Teodoro, e o espírito, que vai satisfazê-la, mas que representa todos os vícios antigos de Vadinho. De fato, nesse confronto da matéria e espírito é possível enxergar um duplo sentido: a matéria, em outro lado, pode ser uma necessidade corporal e o sexo, enquanto o espírito pode ser a consciência moral da personagem. Enfim, o conflito que dona Flor vive se deve ao fato de ser um ser social, na relação com a comunidade a que pertence. Ao mesmo tempo, esse dilema é causado por ser um sujeito de desejo próprio.

É interessante que a volta de Vadinho só é possível através de ninguém mais que Flor, por seu desejo: 
-Você? - disse numa zoa cálida mas sem surpresa, como se o estivesse esperando.

No leito de ferro, nu [...] estava Vadinho deitado, a la godaça, e sorrindo lhe acenou com a mão.

- Por que veio logo hoje? - perguntou dona Flor.

- Porque você me chamou. E hoje me chamou tanto e tanto que eu vim...

- Fiquei contente, muito contente, nem sabes, de te ver... Foi bom demais [...]

[Vadinho]- Só tu podes me mandar embora. Enquanto me quiseres, me desejares, enquanto puseres em mim teu pensamento, estarei vivo e aqui (AMADO, 2008, p. 360-361, 455).

A volta e a presença do marido morto como fantasma não espantam dona Flor, como se fosse uma consequência natural de seu desejo carnal depois do luto. Em forma de espírito, ainda nu, Vadinho ganha mais força para fazer todos os tipos de malandragens, mais do que quando vivo - uma forma de "vida" mais carnavalesca do que nunca. Flor rejeita ter relação sexual com Vadinho não por impossibilidade (já que ele é apenas espírito), mas por sua consciência moral, por sua honra: "Você se esqueceu, Vadinho, que sou mulher casada e que sou séria? Só quem pode botar a mão em mim é meu marido... [...] Tu bem sabe que sou mulher honesta" (AMADO, 2008, p. 361).

A confusão causada no interior de Flor, por outro lado, ajuda a evolução pessoal da personagem, a virar um sujeito com mais poder e expressão sexual; após reencontro com o primeiro marido, ela viola a regra de relação sexual estabelecida pelo segundo e começa a expressar mais sua sexualidade. Também mostra decisão mais independente em relação ao papel social da mulher; ela aconselha Marilda a escolher profissão em lugar de noivado. Podese considerar que a figura de dona Flor, criada por Jorge Amado, supera o sistema social imposto às mulheres e seus papéis daquela época (DA SILVA, 2012, p. 43). Dona Flor, ao fazer a sua escolha final de viver com os dois maridos, entre dois valores opostos, posicionase além do dualismo.

De fato, esse conflito de valores distintos não é apenas de dona Flor, mas da cidade inteira. A cidade baiana é um espaço de dualismo que causa conflito entre valores opostos: entre a honra e o desejo, o corpo e o espírito, costumes e leis, ruas e casas, amor livre e casamento, branco e negro, candomblé e igreja católica, orixás e freiras, o morto e o vivo, funcionário público e jogador, polícia e vagabundo, a virgem e a viúva, etc. Percebemos que os conflitos e dilemas existem também mesmo dentro de um indivíduo. Vadinho é um homem branco que representaria valores europeus, mas seu comportamento é de malandro, um traço da cultura popular brasileira. Sendo filho ilegítimo de uma família importante, Vadinho vive malandragens que não combinam com vida da aristocracia. Por outro lado, existe a 
contradição também nos estilos e ideologia burgueses de Teodoro, que mantêm ordem na casa, pois, apesar do lado tradicionalista em associação farmacêutica, que o posiciona contra a venda de remédios estrangeiros, Teodoro os vende por interesse econômico.

Encontramos um elemento que representa melhor o dualismo espiritual na cidade baiana e no Brasil: o Candomblé. Na obra, a herança cultural africana se mistura com as práticas cotidianas e com a herança cultural colonial, resultando em "uma estampa de São Jorge a matar o dragão" na parede de casa ao lado de "o peji com as armas de Oxóssi, o arco e a flecha, o eruquerê" (AMADO, 2008, p. 17). Após a morte de Vadinho, as mulheres da cidade, à procura do segundo marido de dona Flor, tentam adivinhar quem é o novo candidato por intermédio de videntes, com uma "bola de cristal". Da mesma forma, as pessoas da cidade procuram rituais de macumba como uma forma de resolver problemas. Quando o espírito de Vadinho intervém nos jogos dos seus amigos, um deles diz: "é mesmo coisa do diabo e entregaremos a solução aos macumbeiros" (AMADO, 2008, p. 414). A cultura do Candomblé representa um mundo espiritual baiano de "bruxaria" e "feitiço", coexistindo ao lado da igreja católica. Embora o catolicismo seja a religião oficialmente permitida, esse dualismo de visão do mundo espiritual não gera contradição. Tanto Vadinho, quando vivo, quanto Flor mantêm uma relação íntima com o padre da igreja. $\mathrm{O}$ que pode parecer aos olhares estrangeiros da região uma ironia, na cidade baiana de Amado, é considerado natural.

Lembremos que a cultura de Candomblé, representante da sobrevivência da história afro-brasileira, até certo momento na história brasileira, foi considerada e rotulada oficialmente como um "atraso e desvio dos modelos civilizatórios europeus" (FERREIRA SANTOS, 2009, p. 13). De fato, o Candomblé e a Umbanda como presença de cultura africana na Bahia é um tema bastante recorrente nas obras amadianas. O romancista viu o Candomblé como um produto de mestiçagem: "Todos nosotros somos gente de candomblé, de las religiones populares fetichistas de origen africano $\mathrm{y}$, al mismo tiempo, todos somos católicos" (MARRAS, 1992, p. 168). Assim, a mestiçagem não só se aplica às raças, mas também à cultura do seu povo, ao seu mundo espiritual. É uma aceitação de contradições rotineiras que reflete e intensifica ainda mais a visão utópica do autor de sua cidade-país.

\section{PARA ALÉM DE DUALISMO: AS JANELAS}

O filme de Dona Flor e Seus Dois Maridos estreou em 1976 e foi o segundo maior sucesso na história do cinema brasileiro. A imagem de dona Flor, interpretada pela atriz Sônia Braga, logo se tornou um símbolo de beleza sensual da mulher brasileira, não apenas 
fisicamente. Foi também a encarnação de "todo um ideário de comportamento e vitalidade dos brasileiros" (LEGG, 2015, p. 203-204). Embora tenha recebido elogios, o filme também foi alvo de críticas por realçar o exotismo e o pitoresco da sátira pequeno-burguesa ao representar a imagem do Brasil. Para olhares estrangeiros, na Europa principalmente, o filme significara o fim de Cinema Novo (GOMES, 2018, p. 238-239).

Encontramos no filme um dualismo de espaços na cidade: a casa e a rua. $\mathrm{O}$ filme de Barreto faz uma interpretação fiel à obra literária, a cidade baiana e sua vida cotidiana em cores vivas. O filme começa, assim como o romance, com a cena de morte de Vadinho e logo depois o funeral realizado na casa de Flor e Vadinho. O ambiente pesado e triste do funeral em casa e a recordação de memória do finado marido contrastam com o a alegria do Carnaval na rua. Nós, os espectadores, contemplamos esse contraste através da janela, tanto do interior da casa para fora, quanto o inverso. A casa vira um espaço de morte, enquanto a rua é o de vida. Esse tipo de contrastes de espaços entre casa e rua, além do contraste principal entre Vadinho e Teodoro, uma figura carnavalesca e outra quaresmal, repete-se ao longo do filme. A proposta de casamento e as festas dadas por Teodoro acontecem sempre dentro de casa. Seu trabalho, a "farmácia cientifica", também pode ser considerado como uma extensão da casa, já que é um espaço onde dominam as regras impostas por ele mesmo. Em oposição a essa rotina, Vadinho, quando vivo, passa a maior parte de seu tempo na rua e aí morre. Teodoro é admirador de música clássica, cuja natureza é ser uma prática de ambientes fechados. Já a música apreciada por Vadinho é o samba, música de carnaval e o canto de serenata na rua.

Esse contraste de dois espaços de vida pode ser interpretado como outra forma de dualismo que ajuda a explicar a sociedade brasileira. No ensaio "A casa, a rua, e o trabalho" em $O$ Que Faz o brasil, Brasil?, DaMatta afirma que, no Brasil, a casa e a rua são mais que lugares físicos, pois representam um certo valor dos brasileiros. Segundo ele, em casa está proibido o trabalho, a disputa política e, inclusive, os atos comercias. A rua, opostamente, é o lugar onde não existe um indivíduo perante representantes de lei. Para ele, a casa e a rua não são necessariamente se contrapõem, mas complementam-se como os dois lados de moedas (DAMATTA, 1986, p. 30). Dessa forma, consideramos que na cultura brasileira existe o dualismo de espaços distintos, cada qual com seu papel e significado social.

Como vimos, na cidade baiana, representada no filme, a casa e a rua se encaram e até se refletem através da janela. A existência da janela, além de relembrar os contrastes contínuos ao longo do filme, como na cena de funeral, intermedeia esse dualismo, aliviando as tensões geradas por ele. Podemos observar que, no filme, Vadinho passa bastante tempo sentado em cima da janela da casa olhando o movimento na rua. Nas cenas de amor com dona 
Flor, nos momentos que deveriam ser mais íntimos do casal, as janelas ficam abertas e, por elas, o som do ato chega até os ouvidos das freiras que andam na rua. A vida "na janela" ganha um significado: não se separa a vida formal e a vida pessoal. Vadinho, por viver com as janelas abertas, tenta ignorar o tabu de misturar os valores de dois espaços. É por essa razão que dona Magnolia, uma mulher que fica na janela chamando atenção dos homens que passam na sua rua, vira alvo de fofocas entre as damas da cidade. Dona Magnolia, por seu comportamento imoral de não separar os dois espaços, é oficialmente difamada.

Contrastando com esse cenário, durante o segundo casamento com Teodoro, a casa de dona Flor mantém as janelas fechadas, inclusive nos momentos de amor. Se compararmos essa interpretação com a da outra versão mais recente, estreada em 2017, sob direção de Pedro Vasconcelos, percebemos que não se deu relevo especial à janela. Nessa nova versão, a existência de janelas como mediador entre valores distintos não é tratada como um elemento importante. Nela, as janelas da casa de Flor e Vadinho estão escondidas atrás de cortinas. Além disso, em uma cena de amor entre Flor e Vadinho, um dos momentos mais sensuais, nós, espectadores, olhamos o casal entre as cortinas pouco abertas, como se fosse um ato de voyeurismo. Outra grande diferença da nova versão do filme é o ritual de Candomblé: a cena do ritual para impedir Vadinho de permanecer no mundo material é descrita como um momento espantoso, como "malévola feitiçaria" e "atraso de civilização" (ARAUJO, 2017).

Nesse dualismo de casa e rua, há uma exceção; a escola de culinária de dona Flor. Suas aulas, que devem ser consideradas como um ato social e comercial, são dentro de sua residência, ou seja, ela traz seu negócio para o interior de seu lar. Ironicamente, por trabalhar em casa, ela consegue ficar em uma sobreposição de espaços, de certa forma não respeitando o papel tradicional de mulheres, imposto pela sociedade daquela época, já que é uma mulher que se sustenta sem a ajuda do marido e não se preocupa em ter filho no casamento.

Em Dona Flor, tanto no romance quanto na interpretação cinematográfica, além do dualismo de valores, existe o terceiro lugar que alivia os conflitos entre as dualidades: a mestiça entre branco e negro, a janela entre a casa e a rua, e a escolha final de dona Flor com dois amores. Dessa forma, o autor traz um locus de intermediação que soluciona a "transição entre tradição e modernidade" (DAMATTA, 2008, p. 465) e torna a procura dessa "brasilidade" uma forma para dissolver os conflitos da sociedade brasileira. 


\section{CONCLUSÃO: A BUSCA DE “BRASILIDADE” INACABADA}

Em Dona Flor a cidade de Salvador serve como um espaço simbólico. Se considerarmos a cidade como um pequeno modelo do país, encontramos a "brasilidade", em sentido reduzido, como uma sociedade formada com base na "miscigenação" racial e cultural. Nela, encontramos a visão de identidade brasileira do autor. Para Amado, a existência de um terceiro intermediador reconcilia o dualismo na cultura baiana, repleta de "batalha" de dilemas entre o material e o espiritual e o tradicional e o moderno.

Nas próprias palavras do autor, a essência de sua literatura é "expresión de la brasilidad" (LORENZ, 1972, p. 405). A visão utópica de mestiçagem em Dona Flor vira alvo de crítica, já que acaba escondendo dimensões mais complexas da experiência histórica dos vários indivíduos e grupos que têm formado o país. Como uma forma de procura de identidade nacional, encontramos em Dona Flor, a cidade baiana representada como um espaço de diversos humanos, onde se destacam seu caráter mestiço, a miscigenação entre raças e a cultura mestiça como seu resultado. No seu centro, está dona Flor, uma alegoria de "brasilidade".

O Brasil é, no olhar da Coreia, o país do Carnaval, de corpos belos, natureza exótica, liberalismo de vida, alegria da música e dança. Essa imagem é a primeira que nos chama a atenção num primeiro momento. Porém, o Brasil real é um país que vai muito além disso. Após a leitura da obra de Jorge Amado, vemos que há conflitos, ora antagonismo, ora reconciliação, ou ainda uma terceira possibilidade que é a acomodação à situação como ela é. Pode-se dizer que isso ocorre também em outras sociedades. Isso também ocorre num país como a Coreia do Sul, que viveu um processo de modernização muito rápido após guerra civil, o que resultou num país dividido em dois. Mais recentemente, com a crescente imigração, vivemos o conflito com a entrada de vários povos e culturas, o que desafia o "mito" de povo de raça única, um dos fortes elementos do nacionalismo da Coreia. E tendo a base do nacionalismo coreano abalada, torna-se necessária a redefinição da identidade nacional, a busca de elementos que carregam o povo coreano. Nesse sentido, Dona Flor, com sua questão de identidade de cidade-país, oferece um olhar distinto, mas precioso para uma busca de "verdadeiro rosto" da Coreia. A imagem nacional está em mudança contínua. Por essa razão, sempre vale a pena uma nova leitura. 


\section{REFERÊNCIAS}

AMADO, Jorge. Dona Flor e seus Dois Maridos: história moral e de amor. São Paulo: Companhia das Letras, 2008.

ARAUJO, Inácio. Nova versão de Dona Flor se perde em clichês e roteiro falho. Folha de S. Paulo. 9 dez. 2017. Disponível em:http://www1.folha.uol.com.br/ilustrada/2017/12/1941814nova-versao-de-dona-flor-se-perde-em-cliches-e-roteiro-falho.shtmlAcesso em 01 out. de 2019.

DAMATTA, Roberto. O Que Faz o brasil, Brasil?. 2.ed. São Paulo: Rocco, 1986.

Posfácio. In: Dona Flor e seus Dois Maridos. São Paulo: Companhia das Letras, 2008, p. 463-469.

DA SILVA, Eduardo. Quem dá as ordens? A imagem transnacional da mulher brasileira em Dona Flor, Gabriela e Tieta. In: The Proceedings of the UCLA Department of Spanish and Portuguese Graduate Conference, 2012, v. 1, n. 1, p. 33-49.

DE CASTRO, Juan. Mestizo Nations. Tucson: University of Arizona, 2002.

DE OLIVEIRA, Maurício Sellmann Soares. The Construction of a City: Salvador in the Writings of Jorge Amado. Tese doutoral. Manchester: Manchester University, 2013.

FERREIRA SANTOS, Edmar. O Poder dos Candomblés: Perseguição e Resistência no Recôncavo da Bahia. Salvador: Universidade Federal da Bahia, 2009.

GATES, Henry Louis. Black in Latin America. New York: New York University, 2011.

GOMES, Regina. Dona Flor e seus Dois Maridos e a recepção histórica da crítica. Significação: Revista de Cultura Audiovisual, 2018, v. 45, n. 49, p. 231-246.

GRANADOS SEVILLA, Alan Edmundo. El sonido y la música como marcos de la memoria colectiva. In: GRANADOS SEVILLA Alan Edmundo y HERNÁNDEZ PRADO, José (Coord.). Apreciaciones socioculturales de la música. México: Universidad Autónoma Metropolitana, 2016, p. 151-166.

HALBWACHS, Maurice. A memória coletiva. Trad. Laurent Léon Schaffter. 2.ed. São Paulo: Edições Vértice, 1990.

LEGG, Benjamin. The Bicultural Sex Symbol. In: Performing Brazil: Essays on Culture, Identity, and the Performing Arts. Madison: The University of Wisconsin, 2015.

LORENZ, Günter W. Entrevista com Jorge Amado, In: Diálogo con América Latina: Panorama de una literatura del futuro. Barcelona: Editorial Pomaire, 1972, p. 393-413.

MARRAS, Sergio. América Latina: marca registrada. Buenos Aires: Editorial Zeta, 1992.

MORITZ SCHWARCZ, Lilia. O artista da mestiçagem. In: MORITZ SCHWARCZ, Lilia e 
SELTZER GOLDSTEIN, Ilana (Eds.). O universo de Jorge Amado. São Paulo: Companhia das Letras, 2009, p. 34-45.

Recebido: 06/11/2019

Aprovado: 01/06/2020 